\title{
Penciptaan Naskah Drama Narcissus Berdasarkan Mitologi Yunani
}

\author{
Titis Rahayuningtiar ${ }^{1}$ \\ Jurusan Teater, Fakultas Seni Pertunjukan, Institut Seni Indonesia Yogyakarta
}

\begin{abstract}
ABSTRAK
Naskah drama Narcissus adalah sebuah naskah drama dengan genre klasik yang mengusung irama tragis. Narcissus adalah sebuah tokoh yang berasal dari cerita mitologi Yunani. Narcissus merupakan seorang pemuda sombong yang sangat mengagungkan keindahan yang ada dalam dirinya. Hingga suatu hari Narcissus dikutuk untuk jatuh cinta pada bayangannya sendiri. Penciptaan naskah drama Narcissus bertujuan untuk mengisi kelangkaan naskah drama yang sumber idenya berasal dari fenomena narsis di masyarakat dan konsep irama tragis dalam mitologi Yunani. Metode penciptaan mengusung sebuah metode kreatif yang terdiri dari tahap eksplorasi, pembentukan dan improvisasi. Hasil penciptaan naskah ini adalah sebuah naskah bergenre klasik yang memiliki pesan moral bahwasanya seseorang yang menganggap dirinya sempurna akan memberi akibat buruk untuk dirinya sendiri. Kesempurnaan hanyalah milik Tuhan.
\end{abstract}

Kata kunci: Narcissus, Yunani, mitologi.

\section{ABSTRACT}

The Creation of the Drama Script of Narcissus Based on the Greek Mythology. The script of Narcissus drama is a script of drama with a classical genre which carries the tragic rhythm on it. Narcissus is a character in the story of the Greek Mythology. He is an arrogant young man who really likes to glorify himself on the beauty of what he has. Unfortunatelly, one day he was cursed to fall in love with his own reflection. The creation of drama script of Narcissus is aimed to fill the scarcity of drama scripts in which the basic sources of idea come from narcissistic phenomena in a society and the concept of the tragic rhythm in the Greek mythology. The method of creation brings a creative method comprising the steps of exploration, creation, and improvisation. The result of this script creation is a classical genre script which has a moral message in which a person who considers himself perfectly will give a bad impact to himself. Nevertheles, perfection belongs to God only.

Key words: Narcissius, Greek, mythology

\section{Pendahuluan}

Narcissus merupakan sebuah naskah drama yang terinspirasi dari sebuah film yang berjudul Percy Jackson and The Olympians. Film Percy Jackson and The Olympians yang merupakan film adaptasi dari sebuah novel berseri dengan judul yang sama karya Rick Riordian disutradari oleh Crish Columbus pada tahun 2010. Dalam film fiksi tersebut dikisahkan sebuah kehidupan era modern saat ini dengan unsur cerita mitologi Yunani. Berbagai kejadian yang mengejutkan, penghianatan, dan pertempuran yang merupakan wujud ramalan besar banyak mewarnai kisah dalam film ini. Inti dari cerita dan permasalahan dalam film ini mengenai Percy Jackson dan para anak keturunan dewa berusaha mempertahankan Olympus dari pasukan yang dipimpin oleh Kronos tanpa bantuan dewa dewi Olympia. Kekhawatiran memuncak ketika Kronos dan sekutu para Titan menyusun strategi penyerangan. Seluruh anak keturunan dewa bersiap untuk melakukan pertempuran. Percy dan kawan-kawan hampir tidak memiliki harapan kecuali satu jalan keluar yang ditawarkan Nico sang putra Hades. Namun jika keberuntungan tidak berpihak padanya, tindakan itu bisa berujung pada kematian dan kemusnahan bangsa Olympia. Cerita mitos yang disuguhkan dalam film maupun novelnya itu dikemas dengan membubuhkan cerita-cerita fiksi tetapi tidak meninggalkan mitos Yunani yang berkembang di masyarakat.

Penciptan naskah drama Narcissus ini merupakan sebuah respon dari fenomena sosial yang terjadi dalam masyarakat saat ini. Sering kali kita menyaksikan anak muda di zaman sekarang yang mengagumi dirinya sendiri. Sebutan populernya adalah narsis, contoh kecil misalnya memasang foto-foto yang menunjukan kemolekan dan pose terbaik di jejaring sosial maupun media sosial lainnya. Foto-foto pribadi yang semestinya

1 Alamat Korespondensi: Prodi Teater ISI Yogyakarta. Jalan Parangtritis KM. 6,5 Sewon, Yogyakarta. Telepon 0274-375380. E-mail: titisrahayuningtiar@yahoo.com 
menjadi koleksi sendiri dipamerkan secara sengaja sehingga bisa dikonsumsi oleh publik. Pada dasarnya narsis tidak negatif selama masih berada dalam batas kewajaran, akan tetapi akan menjadi permasalahan ketika sesuatu yang terlalu kita banggakan itu mendapat respon maupun komentar dan menjadikan diri kita semakin merasa tinggi atau pun sebaliknya.

Menurut Mitchell J.J dalam bukunya The Natural Limitation of Youth dampak negatif dari narsis contohnya adalah kecenderungan mengharapkan perlakuan khusus, kurang bisa berempati terhadap orang lain, sulit memberikan kasih sayang, belum mempunyai kontrol moral yang kuat, dan kurang rasional. Namun narsis juga mempunyai dampak positif contohnya seperti dapat meningkatkan percaya diri karena dengan ini mereka mampu menunjukkan jati diri mereka sendiri dan berani untuk tampil beda didepan publik. Dampak positif lainnya tidak bergantung kepada orang lain baik itu secara pribadi dalam hal prestasi, kemauan dan lain-lainnya. Fenomena seperti ini lah yang diangkat sebagai karya yang dituangkan dalam sebuah naskah drama. Sebuah cerita dari mitologi Yunani yang menerangkan asal mula kata narsis. Narsis adalah cinta diri yang berlebihan; (tumbuhan) bunga daerah subtropics (Darmawan, 2011:475). Narsisme adalah sikap tindak mencintai diri sendiri secara berlebihan (Darmawan, 2011:475). Narsis berasal dari kata Narcissus, Narcissus merupaka tokoh dalam mitologi Yunani yang mati karena terlalu mencintai dirinya sendiri. Setelah Narcissus mati di dasar kolam, tumbuhlah sebuah bunga yang sangat cantik di atas kolam itu. Hingga saat ini bunga itu dikenal dengan nama bunga Narcissus atau dalam bahasa ilmiahnya bunga Daffodil. Dalam psikologi istilah narsis pertama kali digunakan oleh Sigmund Freud untuk menggambarkan individu-individu yang menunjukan cinta diri yang berlebihan. Freud manamakan the narsissist dan pelakunya disebut individu narsistik atau seorang narsis.

Andrew Morrison berpendapat bahwa dimilikinya sifat narsis dalam jumlah yang cukup akan membuat seseorang memiliki persepsi yang seimbang antara kebutuhannya dalam hubungannya dengan orang lain (Morrison, 1997:5). Namun apabila jumlahnya berlebihan, dapat menjadi suatu kelainan kepribadian yang bersifat patologis. Kelainan kepribadian atau bisa disebut juga penyimpangan kepribadian merupakan istilah umum untuk jenis penyakit mental seseorang, dimana pada kondisi tersebut cara berpikir, cara memahami situasi dan kemampuan berhubungan dengan orang lain tidak berfungsi normal. Kondisi itu membuat seseorang memiliki sifat yang menyebabkannya merasa dan berperilaku dengan cara-cara yang menyedihkan, membatasi kemampuannya untuk dapat berperan dalam suatu hubungan. Seseorang yang narsis biasanya memiliki rasa percaya diri yang sangat kuat, namun apabila narsisme yang dimilikinya sudah mengarah pada kelainan yang bersifat patologis, maka rasa percaya diri yang kuat tersebut dapat digolongkan sebagai bentuk rasa percaya diri yang tidak sehat, karena hanya memandang dirinya lah yang paling hebat dari orang lain tanpa bisa menghargai orang lain.

Naskah drama Narcissus menggunakan konsep irama tragedi dari mitologi Yunani yang dalam pengadegannya tidak banyak menggunakan adegan tragis meskipun pada dasarnya sama-sama mengusung tragedi. Tragedi Yunani terdiri dari beberapa episode yang diselingi dengan ode-ode yang dinyanyikan bersama (koor). Episode ini hanya digambarkan sebanyak-banyaknya oleh tiga aktor di pentas, setidak-tidaknya sampai sekitar tahun 400 BC, koor menyanyikan ode dan menari dengan iringan musik (Sumardjo, 1986:4). Dalam naskah drama Narcissus terdapat koor yang juga terdapat dalam naskah Oidipus. Koor dalam naskah drama Narcissus diartikan sebagai bisikan baik dan bisikan buruk yang merupakan sisi lain dari suara hati tokoh.

Narcissus merupakan sebuah naskah yang diciptakan berdasarkan kisah dari mitologi Yunani. Naskah ini bercerita tentang asal mula bunga Narcissus (Daffodil) dan fenomena narsis (Mengagumi diri sendiri) yang berkembang di masyarakat. Pada awalnya penciptaan naskah ini terinspirasi dari film dan buku yang bercerita tentang mitologi Yunani. Cerita yang terkandung dalam naskah ini merupakan sebuah kisah yang diambil dari salah satu mitologi Yunani, akan tetapi menambahkan jalan cerita yang imajinatif. Sigmun Freud berpendapat bahwa mencintai diri sendiri adalah pelengkap libidinal dengan egoisme dari naluri mempertahankan diri (Freud, 1975:74). 
Freud membedakan narsisme menjadi dua jenis yaitu narsisme primer dan narsisme sekunder. Narsisme primer merupakan sebuah tahap perkembangan moral pada masa bayi awal menuju keadaan keterikatan obyek, sedangkan narsisme sekunder merupakan individu-individu yang bermasalah secara regresif menggunakan dirinya sendiri, bukan orang lain secara obyek cinta (Freud, 1975:74). Kita semua memiliki dorongan untuk memelihara diri kita sendiri dan untuk melindungi diri dari bahaya, impuls terikat dengan keinginan kita, dan kita tidak bisa memisahkan keinginan seksual kita (diarahkan pada manusia lainnya) dari keinginan kami dalam hati diarahkan untuk merawat diri kita sendiri. Freud menyebutnya hasrat, dasar seksual dibebankan diarahkan pada narsisisme primer atau normal diri. Menurut Mukarovsky dan Felix Vidicka karya sastra adalah proses komunikasi, fakta semiotik, terdiri atas tanda, struktur dan nilai-nilai. Karya seni adalah petanda yang memperoleh makna dalam kesadaran pembaca (Ratna, 2008:93). Strukturalisme adalah paham yang mengatakan bahwa kenyataan tertinggi dari realitas adalah struktur. Sedangkan struktur sendiri adalah hubungan mutual dari kontituten, bagianbagian, atau unsur-unsur pembentuk keseluruhan, sebagai penyusun sifat khas, atau karakter dan koeksistensi dalam keseluruhan bagian-bagian yang berbeda (Norris, 2009:8). Secara definitif strukturalisme memberikan perhatian terhadap unsur-unsur karya. Setiap karya sastra baik karya sastra dengan jenis yang sama maupun berbeda, memiliki unsur yang berbeda. Unsur-unsur drama diantaranya tema, dialog, peristiwa atau kejadian, latar atau setting, penokohan atau perwatakan alur atau plot dan gaya bahasa.

Premise: a proposition antecedently supposed or proved; a basis of argument. A proposition stated or assumed as leading to a conclusion (Egri, 1960:2). Artinya "Premis: sebuah masalah yang mendahului dugaan; sebuah argumen dasar. Sebuah masalah dipaparkan sebagai sesuatu yang penting untuk menuju pada sebuah kesimpulan". Premis adalah rumusan intisari cerita sebagai landasan ideal dalam menunjukkan arah tujuan cerita, ditinjau dari pelaksanaan merupakan landasan pola bangunan lakon (Harymawan1988:24). Dari pengertian-pengertian mengenai premis diatas maka premis dapat dikatakan sebagai sebuah ide dari cerita yang secara singkat dituliskan dalam satu kalimat sehingga dapat menjelaskan tujuan dari cerita. Ketika melakukan sebuah penelitian atau riset mengenai karya yang akan diciptakan, tentu sudah mempunyai ide atau garis besar cerita. Ringkasan cerita inilah yang akan mejadi dasar dalam pembentukan plot cerita. Premis sebaiknya ditulis dengan bahasa yang puitis karena merupakan pesan yang ingin disampaikan lewat cerita.

Every good play must have a well formulated premise. There may be more than one way to phrase the premise, but however it is phrased, the thought must be the same. Playwright usually get an idea, or are struck by an unusual situation, and decide to write a play around it (Egri, 1960:6).

Setiap drama yang baik harus memiliki sebuah premis yang diformulasi dengan baik. Disana mungkin ada lebih dari satu frase untuk premis, tapi bagaimanapun juga itu adalah sebuah frase, harus sama dipikirkan. Penulis naskah biasanya mendapat sebuah ide atau situasi yang luar biasa, dan memutuskan untuk menulis sebuah cerita di sekitarnya.

Begitu juga dengan penciptaan naskah drama Narcissus ini berdasarkan ide-ide yang di dapat dari lingkungan yang ada di sekitar. Mengagumi diri sendiri secara berlebihan akan menimbulkan sebuah bencana dan penderitaan. Kalimat tersebut merupakan premis yang digunakan dalam naskah drama Narcissus. Tokoh utama dalam naskah tersebut adalah seorang pemuda bernama "Narcissus" yang memiliki sifat yang sangat sombong. Berdasarkan premis tersebut banyak karakter yang terdapat dalam naskah Narcissus adalah karakter yang sangat membanggakan kelebihan dirinya sendiri. Selain "Narcissus" yang begitu bangga dengan keindahan yang ada di dalam dirinya, Zeus sang dewa petir juga begitu berkuasa dan merasa bahawa dirinya adalah penguasa dari segalanya.

Zeus begitu bangga dengan kehebatan petirnya dan sanggup melakukan apapun yang dikehendakinya. Tokoh Hera yang merupakan istri dari Zeus juga memiliki karakter yang sangat membanggakan dirinya sebagai ibu dari segala dewa. Hera merasa bahwa dirinya adalah yang 
paling cantik dan berkuasa atas semua nimfa. Sehingga dia mengutuk seorang nimfa bernama Ekho yang lebih cantik dari dirinya. Begitu pula dengan Ares sang dewa perang, dia merasa bahwa kegagahannya seolah tidak dapat dikalahkan oleh siapapun. Hingga ketika Hefaistos suami Afrodit mengetahui peselingkuhan istrinya dengan Ares, Ares tidak merasa bersalah sedikitpun karena menganggap bahwa Hefaistos yang pincang tidak mungkin akan mampu mengalahkan kekuatannya. Tokoh-tokoh dalam naskah tersebut merupakan tokoh dengan karakter yang sangat sombong dan membanggakan dirinya sendiri.

\section{Hasil dan Pembahasan}

Penciptaan naskah Narcissus ini menggunakan metode yang disarankan Hawskin (1992). Pertama, melakukan exploration (eksplorasi), kedua improvisation (improvisasi), dan yang ketiga forming (pembentukan atau komposisi).

\section{Eksplorasi}

Eksplorasi adalah penjelajahan dan penyelidikan (Darmawan, 2011:121). Eksplorasi merupakan sebuah tahapan awal dalam penciptaan naskah drama Narcissus ini. Tahap eksplorasi ini digunakan sebagai rangsangan awal dalam pemunculan ide sebagai dasar penciptaan naskah drama Narcissus. Proses penciptaan naskah ini melalui tahap pembuatan sinopsis, treatment, kemudian naskah. Dalam treatment hanya berupa adegan peristiwa, kemudian dalam proses pembuatan naskah ini dimasukan unsur dialog pada masing-masing tokoh sehingga menghidupkan jalannya peristiwa. Protasis yang merupakan permulaan akan hadir di awal adegan, yaitu ketika "Narcissus" bermimpi mengenai takdir yang akan menentukan kehidupannya. Dalam adegan tersebut diperlihatkan motivasi "Narcissus" dalam mencari jalan untuk memecahkan teka-teki yang selama ini hadir dalam mimpinya. "Narcissus" merasa sangat gelisah ketika mimpi serupa datang berkali-kali dalam tidurnya. Berikut adegannya:

(Narsissus teramat gelisah dalam mimpinya. Semua dewa berlalu dari mimpinya. Dia terbangun dengan keringat yang bercucuran. Wajahnya pucat dan ketakutan. Sementara itu ketiga Dewi takdir kembali muncul dari kepulan kabut dan duduk merajut sebuah kaos kaki besar diatas batu).

\section{Narcissus}

Hah !!! Apa makna semua ini?

(Keadaan sangat mencekam, Narcissus seperti kembali mengingat beberapa sosok dewa yang hadir dalam mimpinya).

Ares.. Sang dewa perang hadir dalam mimpiku. Poseidon dan Apollo juga menyertai bunga tidurku. Hefaistos...??? Hermes...??? Apa maksud pesan yang disampaikan Hermes

Kemudian masuk dalam jalinan peristiwa atau epitasio, dimana dalam perjalanan "Narcissus" menguak semua teka-teki mimpinya hadir tokoh-tokoh yang berkaitan dengan takdir yang akan dilaluinya. Seperti kemunculan tiga dewi takdir Clotho, Lacheisis dan Athropos yang memberi petunjuk kepada "Narcissus" untuk mencari Teirisias. Kemuidan pertemuan Teirisias dengan "Narcissus" adalah sebuah kenaikan konflik yang menjawab teka-teka mimpi "Narcissus" selama ini. Berikut penggalan adegannya:

Narcissus (Semakin mengancam dan hampir menembakan panahnya)

Cepat beritahu semua kepadaku !!!

Teirisias

Baiklah... baiklah... Bertahun-tahun yang lalu, tatkala seorang bayi laki-laki lahir dari seorang nimfa alam semesta aku berkata seperti ini... Hahahaha...aku hendak mewakili bulan dan matahari. Bahwa akan datang bencana panjang di negeri ini. Alam tidak akan ramah lagi seperti biasanya, Gunung... hutan... sungai... laut... bahkan cakrawala enggan bersahabat lagi dengan kalian. Namun 
semua bencana itu akan berakhir... ketika ada sebuah keindahan yang menebus semua bencana itu. Dan satu hal lagi... tatkala putra mungilmu menyongsong kedewasaan, dia hanya akan bisa bernyawa panjang jika putramu itu tidak pernah melihat dirinya sendiri. Hahahahaha !!!

\section{Narcissus}

Apa kau bilang? Kau telah mengutukku? Siapa dirimu? Dewa? Hah... kau bukan siapa-siapa kakek tua. Aku tidak mempercayaimu.

(Narcissus berpikir sejenak)

Jika benar yang kau ucapkan, lalu mengapa harus diriku yang kau kutuk?

Ditengah pergolakan batin "Narcissus", muncul kembali tokoh-tokoh seperti dewa-dewa Olympus, Ekho, Ekhidna dan Nemesis. Jalinan peristiwa diciptakan untuk memperkuat karakter tokoh utama sebagai tokoh sental yang akan membawa jalan cetita hingga titik puncaknya. Salah satu adegan yang diciptakan adalah ketika seorang nimfa bernama Ekho ditirunkan ke bumi karena telah dikutuk oleh dewi Hera yang cemburu padanya. Setelah turun ke bumi Ekho kemudian bertemu dengan "Narcissus", lalu dia jatuh cinta pada "Narcissus". Karena "Narcissus" terlalu sombong, cinta Ekho ditolak dan membuatnya sangat sedih dan menderita. Hingga seorang dewi pembalasan bernama Nemesis mengutuk "Narcissus" akan jatuh cinta pada bayangannya sendiri. Berikut penggalan adegannya:

(Narcissus melangkahkan kakinya ke tepian danau dan hendak minum. Tatkala Narcissus mendekatkan wajahnya di permukaan danau lalu meminum airnya, seperti ada sesuatu yang hilang dari dirinya. Dia menjadi lupa segalanya. Cupid hendak melepaskan panah cinta ke arah Narcissus).

\section{Nemesis}

Lepaskan panah cinta kepada Narcissus.

Wahai putra dewa yang sombong, aku kutuk engkau hanya akan jatuh cinta pada bayangan dirimu sendiri !!!

(Seketika Cupid melepaskan panah cinta kepada Narcissus. Narcisus begitu terkesima menyaksikan bayangan dirinya di permukan danau. Narcissus jatuh cinta pada bayangan dirinya).

Puncak dari cerita ini adalah kehancuran Olympus karena kebijaksanaan para dewa telah sirna. Kemudian "Narcissus" yang telah jatuh cinta pada bayangannya sendiri. Adegan ini merupakan catastasis dalam naskah drama Narcissus. Dimana tokoh utama mengalami konflik yang memuncak setelah melalu jalinan konflik dalam berbagai peristiwa yang telah dialami sebelumnya. Berikut penggalan adegannya:

\section{Narcissus} aku

Mengapa kau terlihat sedih? Jangan pergi... Aku sangat mencintaimu, jangan pernah tinggalkan

(Hening, Ekho terlihat bersembunyi menyaksikan Narcissus yang sedang menatap bayangannya).

Aku tahu !!! Aku akan kesana, kita akan bersama-sama dalam cinta dan bahagia.

Aku akan datang padamu

Aku datang cintaku...

Datang..... untuk bersamamu...

(Narcissus menyeburkan dirinya untuk menggapai bayangannya di permukaan danau. Ekho tak kuasa melihat Narcissus, Ekho menampakkan diri dan menatap Narcissus yang hampir tenggelam. Narcissus menatap Ekho seolah menyadari jika ini semua memang benar takdirnya. Namun apa daya, 
Narcissus yang merana tenggelam bersama bayangan cintanya).

Catastrophe yang merupakan jalinan peristiwa penutup cerita terletak diakhir cerita "Narcissus". Pada akhir cerita, "Narcissus" yang telah jatuh cinta pada bayangannya yang dia lihat di danau berusaha meraih bayangannya itu hingga dia tenggelam dan mati. Ketika "Narcissus" akan tenggelam, dia melihat sosok Ekho yang sedang meratapinya. "Narcissus" seperti teringat kembali dengan ramalan yang dikatakan Teirisias bahwa ajalnya akan ditentukan oleh seorang wanita penuh derita. Ekho terus meratapi kematian "Narcissus" hingga dia membatu.

\section{Pembentukan}

Metode eksplorasi merupakan tahapan proses yang paling ekspresif. Tahap pembentukan merupakan tahapan kedua dalam proses penciptaan naskah drama Narcissus. Berikut tahap pembentukannya:

\section{Tema}

Tema yang diusung adalah "Cinta adalah seimbang, tidak baik mencintai diri sendiri secara berlebihan". Dalam proses penciptaan naskah drama Narcissus, tema yang sudah dirangkai kemudian dikembangkan melalui tahapantahapan yang sudah dilaksanakan dalam metode eksplorasi.

\section{Plot/Alur}

Plot digunakan sebagai sebuah susunan perkembangan peristiwa. Tujuannya untuk memberi kesan tangga dramatik dalam sebuah cerita. Penggunaan teori Aristoteles yang ditulis Harymawan menjelaskan hal berikut:

\section{Protasis}

Protasis merupakan tahap awal permulaan dan motif lakon dalam naskah. Pembentukan yang dilakukan adalah dialog koor atau paduan suara diucapkan dengan nyanyian. Namun tidak semua dialog paduan suara dinyanyikan, beberapa dialog lain diucapkan dengan gaya deklamasi untuk memperkuat jalannya cerita. Setelah itu peristiwa mimpi yang dialami "Narcissus", dimana "Narcissu" dihantui oleh mimpi yang penuh dengan teka-teki. Mimpi itu membawa pesan bahwa "Narcissus" akan segera menyambut takdirnya. Pembentukan tahap awal ini sangat penting karena merupakan sebuah permulaan yang akan menjadi pengarah jalannya cerita hingga akhir.

Epitasio
Epitasio adalah jalinan cerita. Pembentukan dalam tahap ini adalah merangkai jalinan cerita yang telah ada kemudian dikembangkan dengan penambahan-penambahan konflik maupun cerita. Dalam naskah drama Narcissus ini bermula dari kehadiran Teirisias untuk mengutuk "Narcissus" tidak akan bernyawa panjang jika melihat bayangannya serta berbagai bencana yang akan menimpa negeri itu. Tokoh utama dalam naskah yaitu "Narcissus" akan mengalami konflik yang menanjak dari awal cerita hingga akhir cerita. Dalam tahap perkembangan konflik tokoh utama inilah terdapat penambahan cerita dan konflik. Penambahan cerita tersebut antara lain dewa-dewa yang hadir dalam mimpi "Narcissus" sebagai pesan bahwa "Narcissus" akan segera menyambut takdirnya. Bencana terjadi satu per satu, Ameinius mati bunuh diri karena tak kuasa menahan perasaannnya terhadap Narcissus, dan bencana alam terjadi dimana-mana seperti yang dikabarkan oleh dewi takdir. Olympus kacau karena Ekho dikutuk Hera hingga hanya bisa berbicara mengulang kata terakhir karena dituduh berselingkuh dengan Zeus, Ares yang berselingkuh dengan Afrodit, serta banyak bencana lainnya. Ekho yang diturunkan ke bumi jatuh cinta pada "Narcissus" namun ditolak hingga Ekho menderita. Semua jalinan cerita tersebut dibentuk dan dihadirkan untuk memperkuat karakter tokoh utama. Meskipun ada banyak tokoh yang tidak memiliki kontak langsung dengan tokoh utama, setiap konflik atau cerita yang dialami oleh tokoh lain akan mempengaruhi karakter tokoh utama. Proses pembentukan seperti ini akan membantu tokoh utama menanjaki konfliknya.

\section{Catastasis}


Catastasis adalah puncak dari peristiwa hingga mencapai titik klimaks. Puncak klimaks diawali dengan kehancuran Olympus, para dewa telah hancur kebijaksanannya. Ares dan Afrodit pergi meninggalkan Olympus. Selain itu hadir sosok Nemesis sang dewi pembalasan yang mengutuk "Narcissus" akan jatuh cinta pada bayangannya dirinya. Titik klimaks dalam cerita ini adalah matinya "Narcissus" karena terlalu mencintai dirinya sendiri. "Narcissus" tenggelam di danau Donacon yang angker.

\section{Catastrophe}

Catatrophe adalah penutup dari cerita, yakni cerita yang hadir setelah kematian "Narcissus". Saat peristiwa tenggelamnya "Narcissus", muncul sosok Ekho yang menyaksikan "Narcissus" tenggelam. Akan tetapi Ekho tidak dapat berbuat apa-apa untuk menolong "Narcissus" hingga akhirnya "Narcissus" tenggelam Ekho hanya bisa meratapi nasib cintanya. Ini merupakan jawaban dari ucapan Teirisias yang mengatakan bahwa ajal "Narcissus" akan ditentukan oleh wanita yang penuh dengan derita.

Alur yang digunakan dalam naskah ini merupakan alur linier/progresif. Tokoh-tokoh mengalami kenaikan konflik dalam proses jalannya cerita. Dimulai dari pengenalan tokoh dan perjalanannya, kemudian timbul beberapa konflik yang kemudian berujung dengan tragedi kematian "Narcissus" yang merupakan klimaks dari cerita ini.

Gaya Bahasa

Gaya bahasa yang digunakan dalam naskah ini adalah gaya bahasa Indonesia yang puitis dengan gaya permainan yang formal dan agung atau grand style. Gaya bahasa dibentuk untuk menciptakan kesan klasik dalam naskah drama Narcissus.

\section{Sudut Pandang}

Sudut pandang yang digunakan dalam naskah ini adalah sudut pandang orang ketiga. Karena hubungan yang tercipta adalah hubungan pencerita dengan ceritanya. Sehingga pencerita tidak terlibat langsung dalam naskah tersebut.

\section{Tokoh dan Penokohan}

Berikut pembentukan karakter tokoh dalam naskah drama Narcissus:

\section{Tabel 2. Pembentukan Karakter Tokoh}

\begin{tabular}{|c|c|c|}
\hline $\begin{array}{l}\text { Nama } \\
\text { Tokoh }\end{array}$ & Karakter Dalam Mitos & Karakter Dalam Naskah \\
\hline Narcissus & $\begin{array}{l}\text { Anak laki-laki Dewa } \\
\text { Sungai yang tidak } \\
\text { menyukai lawan jenis. }\end{array}$ & $\begin{array}{l}\text { Anak laki-laki Dewa Sungai yang sombong, } \\
\text { pemberani, tidak menyukai lawan jenis. Berusia } 25 \\
\text { tahun. Kulitnya halus, bermata biru dan berambut } \\
\text { indah seperti bulu domba. }\end{array}$ \\
\hline Kefissos & $\begin{array}{l}\text { Dewa Sungai yang } \\
\text { bijaksana. }\end{array}$ & $\begin{array}{l}\text { Dewa Sungai yang bijaksana. Berusia } 100 \text { tahun. } \\
\text { Tidak berambut dan memiliki janggut yang sudah } \\
\text { memutih. }\end{array}$ \\
\hline Liriope & $\begin{array}{l}\text { Istri Dewa Sungai yang } \\
\text { baik. }\end{array}$ & $\begin{array}{l}\text { Istri Dewa Sungai yang berparas cantik, baik dan } \\
\text { penyayang. Berusia } 50 \text { tahun, bertubuh subur. }\end{array}$ \\
\hline Teirisias & Peramal tua yang buta. & $\begin{array}{l}\text { Peramal laki-laki tua yang memberi kutukan pada } \\
\text { Narcissus, buta tetapi pendengarannya tajam. } \\
\text { Berusia } 100 \text { tahun, berjanggut putih dan bungkuk. }\end{array}$ \\
\hline Ekho & $\begin{array}{l}\text { Bidadari berparas sangat } \\
\text { cantik. }\end{array}$ & $\begin{array}{l}\text { Bidadari berparas sangat cantik tetapi hanya bisa } \\
\text { berbicara menirukan kata terakhir orang yang } \\
\text { berada di dekatnya. Berusia } 20 \text { tahun. }\end{array}$ \\
\hline Zeus & $\begin{array}{l}\text { Dewa Petir yang kuat } \\
\text { penguasa Olympus }\end{array}$ & $\begin{array}{l}\text { Dewa Petir yang kuat, agak genit, suka mengelak, } \\
\text { penguasa Olympus. Berusia } 100 \text { tahun, berjanggut } \\
\text { dan berambut putih. }\end{array}$ \\
\hline
\end{tabular}




\begin{tabular}{|c|c|c|}
\hline $\begin{array}{l}\text { Nama } \\
\text { Tokoh }\end{array}$ & Karakter Dalam Mitos & Karakter Dalam Naskah \\
\hline Hera & $\begin{array}{l}\text { Istri Dewa Petir yang } \\
\text { bijaksana. }\end{array}$ & $\begin{array}{l}\text { Istri Dewa Petir yang pencemburu. Berusia } 50 \\
\text { tahun, bertubuh subur, berwajah sinis. }\end{array}$ \\
\hline Nemesis & Dewi Pembalasan. & $\begin{array}{l}\text { Dewi Pembalasan yang usil. Berusia } 100 \text { tahun, } \\
\text { memiliki sayap yang besar, wajahnya buruk dan } \\
\text { menyeramkan. }\end{array}$ \\
\hline Clotho & Dewi Pembawa Takdir. & $\begin{array}{l}\text { Dewi Pembawa Takdir bertubuh sangat gemuk. } \\
\text { Berusia } 100 \text { tahun. }\end{array}$ \\
\hline Athropos & Dewi Pembawa Takdir. & $\begin{array}{l}\text { Dewi Pembawa Takdir bertubuh sangat pendek. } \\
\text { Berusia } 100 \text { tahun. }\end{array}$ \\
\hline Lacheisis & Dewi Pembawa Takdir. & $\begin{array}{l}\text { Dewi Pembawa Takdir bertubuh sangat tinggi dan } \\
\text { kurus. Berusia } 100 \text { tahun. }\end{array}$ \\
\hline Afrodit & $\begin{array}{l}\text { Dewi Cinta berparas } \\
\text { cantik. }\end{array}$ & $\begin{array}{l}\text { Dewi Cinta berparas cantik, genit dan suka } \\
\text { menggoda. Berusia } 30 \text { tahun. }\end{array}$ \\
\hline Cupid & Anak Dewi Cinta. & $\begin{array}{l}\text { Anak Dewi Cinta bertubuh kecil dan memiliki } \\
\text { sayap, usil tetapi baik hati. Berusia } 5 \text { tahun, } \\
\text { memiliki sayap. }\end{array}$ \\
\hline Ares & Dewa Perang & $\begin{array}{l}\text { Dewa Perang yang gagah perkasa. Berusia } 30 \\
\text { tahun. }\end{array}$ \\
\hline Demeter & Dewi Kesuburan & $\begin{array}{l}\text { Dewi Kesuburan bertubuh besar dan cantik. } \\
\text { Berusia } 50 \text { tahun. }\end{array}$ \\
\hline Poseidon & Dewa Laut & $\begin{array}{l}\text { Dewa Laut yang gagah dan bijaksana. Berusia } 100 \\
\text { tahun, berjanggut putih dan memiliki ekor yang } \\
\text { besar. }\end{array}$ \\
\hline Hestia & Dewi Perapian & $\begin{array}{l}\text { Dewi Perapian yang sedikit cerewet. Berusia } 50 \\
\text { tahun. }\end{array}$ \\
\hline Hermes & Dewa Pembawa Pesan & $\begin{array}{l}\text { Dewa Pembawa Pesan yang selalu pelupa. Berusia } \\
30 \text { tahun. }\end{array}$ \\
\hline Hefaistos & Dewa Pandai Besi & $\begin{array}{l}\text { Dewa Besi yang sering dibodohi oleh istrinya. } \\
\text { Berusia } 30 \text { tahun. }\end{array}$ \\
\hline Artemis & Dewi Perburuan & $\begin{array}{l}\text { Dewi Perburuan yang pemberani dan liar. Berusia } \\
20 \text { tahun. }\end{array}$ \\
\hline Apollo & Dewa Musik & $\begin{array}{l}\text { Dewa Musik yang berparas sangat tampan dan } \\
\text { pandai memainkan lyra. Berusia } 20 \text { tahun. }\end{array}$ \\
\hline Athena & Dewi Kebijaksanaan & $\begin{array}{l}\text { Dewi Kebijaksanaan yang cantik dan anggun. } \\
\text { Berusia } 30 \text { tahun. }\end{array}$ \\
\hline Ekhidna & Ibu Semua Monster & $\begin{array}{l}\text { Manusia Setengah Ular yang genit. Wujudnya } \\
\text { menyerupai putri duyung. Wanita dengan ekor } \\
\text { panjang dan bersisik. }\end{array}$ \\
\hline
\end{tabular}




\section{Latar/Setting}

Setelah membentuk tema, alur, penokohan, sudut pandang dan gaya bahasa dalam naskah, pada tahap ini dilakukan sebuah proses pembentukan dengan latar atau setting. Penciptaan latar yang akan diaplikasikan dalam pertunjukan disesuaikan sehingga mencapai sebuah kesatuan bentuk. Pada setiap drama ataupun karya sastra lainnya memiliki latar cerita dimana sebuah peristiwa terjadi. Latar Biasanya meliputi tiga dimensi, yaitu tempat, ruang dan waktu.

\section{Latar Tempat}

Latar tempat yang digunakan dalam naskah drama Narcissus adalah bukit Olympus dan hutan dimana terdapat sebuah danau yang besar. Dalam penentuan latar tempat telah dipertimbangkan sesuai dengan kondisi tempat dimana naskah ini akan dipentaskan. Olympus dilambangkan sebagai dunia atas yang menjadi tempat tinggal para dewa yang memiliki kekuatan dan kelebihan yang tidak dimiliki oleh manusia. Pilar-pilar kokoh yang berdiri di puncak Olympus terlihat sedikit rapuh karena telah berkurangnya kebijaksanaan para dewa. Para dewa dapat menginjakan kaki dimana saja karena memiliki kedudukan yang lebih tinggi dibanding manusia, tetapi manusia tidak dapat menginjakan kaki di Olympus karena hanya manusia yang terpilih dan dikendaki dewa saja yang dapat menginjakan kaki disana. Hutan dan danau dilambangkan sebagai dunia bawah langit dimana manusia tinggal. Pohon-pohon dihadirkan disertai dengan sungai kecil dan batu yang ada di sekelilingnya. Danau yang dihadirkan merupakan tempat dimana "Narcissus" menemui ajalnya. Sesuai dengan konsep penciptaan yang mengusung tragedi klasik, dialog yang telah diciptakan dalam naskah diolah sedemikian rupa oleh aktor dan sutradara. Sutradara dan aktor sangat berperan penting. Sutradara akan mengarahkan aktor untuk mencapai apa yang diinginkan dalam naskah dan aktor yang akan mengolah dan menghidupkan naskah. Pengolahan aktor dan latar tempat dilakukan oleh sutradara agar makna dan pesan yang terkandung dalam naskah dapat dipertanggung jawabkan dan dapat dicerna oleh masyarakat yang tidak lain adalah penonton pertunjukan.

\section{Latar Ruang}

Hutan dan danau dalam naskah drama Narcissus berada di luar ruangan. Latar hutan dan danau tidak dibatasi oleh dinding ataupun elemen lain. Latar yang berada di luar ruangan ini dihadirkan karena "Narcissus" merupakan seorang pemuda yang sangat senang berburu. Olympus dalam naskah drama Narcissus berada di dalam ruangan. Latar seperti ini dipilih karena kewibawaan dan kelenihan para dewa yang bisa memantau apa saja dari satu tempat. Pakaian yang dipakai para dewa adalah pakaian terbaik. Pilarpilar yang menjulang tinggi dihadirkan untuk memberi kesan bahwa Olympus adalah sebuah istana yang disangga oleh kekuatan yang sangat besar.

\section{Latar Waktu}

Naskah drama Narcissus berisi peristiwaperistiwa yang terjadi di pagi dan sore hari. Kegiatan berburu dan bermain yang dilakukan "Narcissus" terjadi saat matahari belum terbenam. Pada bagian akhir cerita terdapat pergantian waktu dari satu musim ke musim lain. Pada bagian tersebut menceritakan tentang "Narcissus" yang setia memandangi bayangan dirinya di permukaan danau sebelum dia mati menceburkan diri. Semua peristiwa dalam naskah drama Narcissus merupakan kejadian yang terjadi pada masa Yunani kuno. Tidak disebutkan semua peristiwa dalam naskah ini terjadi pada tahun berapa, tetapi disesuaikan berdasarkan kostum yang tergambar dari beberapa lukisan yang menceritakan mitologi ini. Salah satu yang paling terkenal adalah sebuah lukisan berjudul "Narcissus" karya Michael Angelo Merisi.

\section{Improvisasi}

Proses improvisasi diletakan diakhir karena sesuai dengan pengalaman proses yang sudah dilakukan sebelumnya. Berdasarkan metode Creating The Dance yang disebutkan diatas, makan teciptalah sebuah metode kreatif baru yakni eksplorasi, pembentukan dan imrpovisasi. Metode kreatif ini terbentuk ketika melakukan proses penciptaan naskah drama Narcissus. Dalam proses penciptaan naskah terdapat banyak sekali pengembangan-pengambangan yang muncul. Terlepas dari konsep penciptaan naskah sebelumnya, tahap improvisasi ini mem- 
beri kebebasan untuk mengembangkan jalan cerita sehingga menajadi lebih baik. Salah satu improvisasi yang tercipta dalam proses penciptaan naskah drama Narcissus ini adalah terciptanya tokoh-tokoh lain yang dapat menghidupkan suasana dalam adegan. Salah satunya adalah tokoh tiga Ekhidna yang merupakan jelmaan manusia setengah ular peliharaan Dewi Artemis. Proses improvisasi ini lebih menekankan pada perkembangan konflik peristiwa. Dimana tokoh utama mengalami kenaikan konflik yang berarti hingga mencapai titik puncaknya.

Seperti yang dikataan lajos Egri dalam bukunya yang berjudul The Art of Dramatic Writing bahwa dalam membuat naskah konflik dibagi menjadi empat bagian. Yang pertama dalah static, yaitu tidak ada kenaikan konflik yang berarti. Dimana konflik-konflik yang tercipta tidak terlalu mempengaruhi konflik yang dialami oleh tokoh utama. Maka dari itu pengembangan karakter pada tahap improvisasi ini sangat penting. Karena tanpa adanya kekuatan pada masing-masing karakter tokoh, tidak akan tercipta kenaikan konflik yang berarti. Kemudian konflik yang kedua adalah jumping, yang artinya adalah konflik yang melompat. Jika terjadi hal semacam ini, maka harus kembali pada premis yang telah ditentukan sebelumnya. Kemudian memahami kembali dengan logis dan sesuai dengan jalannya cerita. Sekali lagi, pengembangan karakter agar lebih kuat diperlukan dalam tahap improvisasi ini untuk menghindari terjadinya konflik yang melompat. Kemudian konflik yang ketiga adalah slowly rising, dimana para tokoh mengalami kenaikan konflik secara perlahan hingga pada akhirnya akan mencapai puncaknya.

Dalam penciptaan naskah drama Narcissus ini kenaikan konflik tokoh utama sangat diperhatikan. Dari awal hingga akhir adegan, tokoh "Narcissus" mengalami kenaikan konflik secara perlahan. Dimulai ketika "Narcissus" gelisah karena terus dihantui oleh teka-teki yang ada dalam mimpinya, kemudian pertemuannya dengan ketiga dewi takdir yang memberi petunjuk jika dia harus bertemu dengan Teirisias untuk memecahakan semua teka-tekinya. Setelah itu kenaikan konflik berlanjut ketika dia bertemu dengan Teirisias yang mengatakan bahwa "Narcissus" akan mati jika melihat bayangannya sendiri. "Narcissus" menolak apa yang dikatakan Teirisias, hingga konflik terus berlanjut ketika "Narcissus" menolak cinta Ekho. Penolakan "Narcissus" terhadap Ekho adalah gerbang awal dari takdir yang akan segera disambut olehnya.

Puncak konflik terjadi ketika "Narcissus" dikutuk untuk jatuh cinta pada bayangannya sendiri hingga dia harus mati tenggelam di danau Donacon. Konflik yang keempat adalah foreshadowing, yaitu sebuah petanda yang akan menjadi kunci dalam rangkaian peristiwa. Foreshadowing dalam naskah ini adalah ketika Teirisias mengatakan kepada "Narcissus" jika ajalnya akan ditentukan oleh seorang wanita penuh derita. Adegan ini muncul di tengah jalannya cerita, hingga menjadi sebuah petanda peristiwa yang akan terjadi pada akhir cerita. Tahapan konflik ini dihadirkan untuk menambah tangga dramatik pada naskah. Karena sebuah konflik tidak ditambahkan begitu saja, tetapi telah dimulai sejak proses sebelumnya diawal cerita.

\section{Hasil Penciptaan}

Proses penciptaan naskah drama Nacissus tidak terlepas dari teori drama secara umum yang menjelaskan tentang tema, dialog, peristiwa atau kejadian, latar atau setting, penokohan atau perwatakan alur atau plot dan gaya bahasa. Semua unsur tersebut telah dijelaskan secara detail sebelumnya. Sapardi Djoko Damono (2005) menjelaskan pemahaman tentang teori teks dan mencipta teks. Konsep-konsep teoritik yang berkaitan dengan pendekatan yang digunakan mengungkapkan bahwa seorang pengarang hanya meniru sebuah teks yang sebelumnya telah ada dan tidak akan bisa menjadi orisinil. Seorang pengarang hanya dapat membuat sebuah adonan baru yang tidak terlepas dari teks-teks yang sudah ada sebelumnya. Dalam proses penciptaan naskah drama Narcissus ini adonan baru yang diciptakan adalah sebuah naskah dengan genre tragedi Yunani klasik.

Adonan naskah drama Narcissus tentu tidak terlepas dari teks-teks yang sudah ada. Karena pola dan gaya bahasa yang digunakan meniru naskah dengan genre yang sama yaitu Trilogi Oidipus (Oidipus Sang Raja, Oidipus di Kolonus, dan Antigone) karya Sopokles. Aristoteles menjelaskan jika tragedi adalah imitasi atau peniruan terhadap sebuah tindakan yang bagus dari seorang tokoh yang besar pengaruhnya, hingga menimbulkan 
rasa kasihan dan ketakutan. Kemudian dalam proses penciptaan naskah drama Narcissus terjadi improvisasi dalam hal pembelokan irama tragis tersebut. Dalam naskah tragedi klasik hanya memperlihatkan penderitaan dan kesakitan, akan tetapi dalam naskah drama Narcisssus ini terdapat cerita lain yang memiliki unsur komedi. Salah satunya adalah adegan ketiga Ekhidna yang ketakutan karena bertemu dengan Dewi Artemis di tengah hutan. Pembelokan irama tragis ini telah memasuki kawasan intertekstualitas, karena Roland Barthes mengatakan jika sebuah teks adalah anyaman baru dari kutipan lama.

\section{Penutup}

Proses penciptaan naskah drama Narcissus ini merupakan sebuah proses yang panjang. Beranjak dari sebuah fenomena sosial yang berkembang di lingkungan sekitar dan terinspirasi dari cerita dalam film yang berjudul Percy Jackson and The Olympians. Proses penciptaan naskah drama Narcissus berlangsung lama, karena berawal dari pengumpulan ide, pencarian raferensi mengenai naskah drama klasik, memahami pengertian dan gejala narsis, membuat sinopsis, membuat treatment dan berlanjut pada naskah. Naskah drama Narcissus ditulis dalam lima tahap. Dalam setiap tahap disebut sebagai draft, dimana terdiri dari draft I, draft II, draft III, draft IV dan final draft. Naskah yang pertama kai dibuat adalah naskah draft I, kemudian seiring berjalannya proses penciptaan berlanjut menjadi draft selanjutnya dan berakhir dengan final draft. Naskah drama Narcissus adalah sebuah naskah drama yang mengusung irama tragis di dalamnya. Irama tragis yang terkandung dalam naskah drama dari Yunani pada umumnya mengusung cerita-cerita yang mengesankan bahwa semua kisah dipenuhi dengan penuh penderitaan. Akan tetapi di dalam naskah drama ini irama tragis yang diciptakan kemudian dibelokkan dengan mengusung irama romantis pada beberapa adegan. Tokoh-tokoh yang diciptakan merupakan tokoh-tokoh yang ada di dalam cerita mitologi Yunani. Banyak pola yang digunakan dalam menciptakan naskah ini meniru naskah tragedi Trilogi Oidipus (Oidipus Sang Raja, Oidipus di Kolonus, dan Antigone) dari mulai penghadiran koor, irama puitik, bentuk naskah dan kenaikan konflik tokoh utama.
Setelah melalui beberapa proses maka terciptalah sebuah naskah drama berjudul Narcissus yang mengungkap sisi gelap seseorang yang memiliki sifat narsis. Naskah drama Narcissus adalah sebuah naskah drama yang menceritakan sosok seorang pemuda bernama "Narcissus" yang memiliki sifat sombong hingga dia harus mati karena mencintai bayangan dirinya sendiri. Cerita mitologi Narcissus ini merupakan asal mula kata narsis yang pertama kali dipopulerkan oleh Sigmund Freud untuk menggambarkan seseorang yang memiliki sifat mengagumi diri sendiri. Dapat diperoleh kesimpulan bahwa naskah drama Narcissus adalah refleksi diri untuk para penonton ketika naskah ini dipentaskan dalam sebuah pertunjukan teater. Bahwasanya jika memiliki sifat terlalu mengagumi bahkan mencintai diri sendiri adalah tidak baik dan akan mengakibatkan sesuatu yang negatif, baik untuk diri sendiri maupun lingkungan sekitarnya.

Menciptakan sebuah naskah drama adalah salah satu bentuk apresiasi yang positif untuk memperkaya khazanah naskah drama di Indonesia. Proses penciptaan naskah ini tidak terlepas dari kesulitan dan kendala. Salah satu kesulitan yang dialami selama menciptakan naskah ini adalah sulitnya membentuk karakter tokoh utama dengan beragam konflik yang dialaminya. Seiring berjalannya proses kesulitan tersebut dapat diatasi dengan pengembangan dialog baik dari tokoh utama itu sendiri maupun dari dialog tokoh lain yang akan mendukung kenaikan konflik dalam cerita naskah drama Narcissus. Kemudian kesulitan lainnya adalah menentukan metode apa yang mudah dicerna dan disesuaikan dengan naskah yang akan diciptakan. Sehingga ketika menemukan sebuah metode lalu dirangkai dan terciptalah sebuah metode kreatif baru, kesulitan tersebut dapat diatasi. Setelah melewati beberapa proses maka saran yang dapat diberikan adalah hendaknya tidak latah dengan karya-karya yang akan diciptakan. Artinya tidak lantas membuat sebuah karya khususnya naskah drama dengan mengusung satu genre sejenis yang sedang populer atau musiman. Sebagai seorang penulis naskah yang cerdas harus mampu menganalisis banyak aspek yang akan menunjang proses penciptaan. Perkaya ide dengan melihat kejadian di lingkungan sekitar, karena bisa saja sebuah ide yang muncul dari sesuatu yang sederhana akan menjadi sebuah karya yang luar biasa dengan analisa yang baik. 
Ide-ide yang didapat dari lingkungan sekitar handaknya tidak ditelan mentah-mentah, tetapi tetap tidak meninggalkan ideologi atau genre cerita yang akan menjadi ciri khas seorang penulis naskah drama.

\section{Kepustakaan}

Darmawan, Hendro. 2011. Kamus Ilmiah Populer. Yogyakarta: Bintang Cemerlang.

Damono, Sapardi. 2011. Ilmu Pengetahuan Budaya dan Tanggung Jawabnya. Jakarta: UI Press.

Freud, Sigmund. 1991. On Narcissism: An Introduction. London: Karnac Books.

Harymawan, RMA. 1988. Dramaturgi. Bandung: Remaja Rosdakarya.

Norris, Christopher. 2009. Membongkar Teori Dekonstruksi Jacques Derrida. Yogyakarta: ArRuzz Media.

Piaget, Jean. 1973. Structuralism. London: Routledge.
Ratna, Nyoman Kutha. 2008. Penelitian Sastra: Teori, Metode dan Teknik. Yogyakarta: Pustaka Pelajar.

Soedarsono RM.2001. MetodologiSeniPertunjukan dan Seni Rupa. Bandung: Masyarakat Seni Pertunjukan Indonesia.

Sumarjdo, Jacob. 1986. Ikhtisar Sejarah Teater Barat. Bandung: Angkasa.

http://www.psikologiums.net/sigmundfreud diuduh 29 September 2012.

http://www.esastra.com/kursus/kepenyairan. htm\#Modul diunduh 30 September 2012.

http://www.muvtizarsolchin.wordpress.com/ page/9 diunduh 30 September 2012.

http://informasitips.com/kenali-lebih-jauh-ciriciri-penderita-narsis/ diunduh 18 Oktober 2012.

http://www.narcissismfree.com/what-isnarcissism.php diunduh 18 oktober 2012. 